\title{
Machinability analysis on helical milling of carbon fiber reinforced polymer
}

\author{
Haiyan WANG*, Xuda QIN** and Hao LI** \\ * School of Control Engineering, Northeastern University at Qinhuangdao, Qinhuangdao 066004, China \\ E-mail: hywang16@126.com \\ ** School of Mechanical Engineering, Tianjin University, Tianjin 300072, China
}

Received 8 June 2015

\begin{abstract}
In the helical milling process, a rotating tool traverses a helical trajectory to generate a hole. In order to investigate the cutting state in helical milling of carbon fiber reinforced polymer(CFRP), experiments were conducted with unidirectional and multidirectional laminates. Cutting forces, tool wear state and hole quality were discussed respectively. The effect of cutting parameters on the cutting forces was first presented, then the influence of different workpiece material on the cutting forces was secondly analyzed. Because of higher abrasion of carbon fiber, tool wear was a major problem without being ignored in the cutting process, so the study on the tool wear state was carried out from the point of wear process, wear form, coated state and change of element etc. Therefore the effect of tool wear on the cutting forces was detailedly analyzed. Next the relation between tool wear and entry delamination of hole-making was discussed. Finally, inner delamination, delamination factor, diameter error, surface roughness and circularity error were also investigated in detail.
\end{abstract}

Key words : Carbon fiber reinforced ploymer(CFRP), Helical milling, Cutting force, Tool wear, Hole quality

\section{Introduction}

Carbon fiber reinforced polymers(CFRPs) are used widely in the aerospace industry due to their superior material properties such as high strength, low weight, high resistance to corrosion, and a low thermal expansion coefficient. CFRPs are two-phase or multi-phase structures composed with fibers and matrix, the reinforcement is usually a combination of carbon fiber layers with different directions. Machining of CFRP is difficult owing to their discontinuity, inhomogeneity and anisotropic nature(Hintze, et al.,2011).

Hole-making is about 50 percent of total processing in the machining scope, so the research of typical hole-making technique about CFRP is very important. The effect of cutting parameters and tool parameters on the cutting force and delamination were studied in the drilling of CFRP(Karnik, et al.,2008; Durão, et.al.,2010), the relationship among cutting force, drilling parameters and tool wear were mainly discussed(Iliescu, et al.,2010).In whole, hole quality and tool wear state were mainly two characteristics in the relative study. Main problems during the drilling process were illustrated as follows: the stress concentration was large at the drilling position, which could easily cause splitting and other defects(Lachaud, et al.,2001); larger linear expansion coefficient and a large elastic recovery made shrinkage phenomenon(Zhang, et al.,2004); high hardness made drill bit worn so badly during drilling process, excessive axial force could cause too large inter-laminar stresses to induce delamination defects(Rawat and Attia,2009).

Helical milling process has been more and more widely accepted in hole-making scope with greater processing advantages, especially for difficult to cut materials. But the structure of CFRP is different to metal, cutting characteristics, such as cutting force, tool wear and hole-quality in the helical milling process need to be detailedly 
analyzed.

In the helical milling process, the tool rotates around its axis with revolving around the center of the hole and keeps the axial feed, so the trajectory of the tool center is spiral, as shown in Fig.1, where point $\mathrm{C}$ is tool center, point $\mathrm{O}$ is hole center.
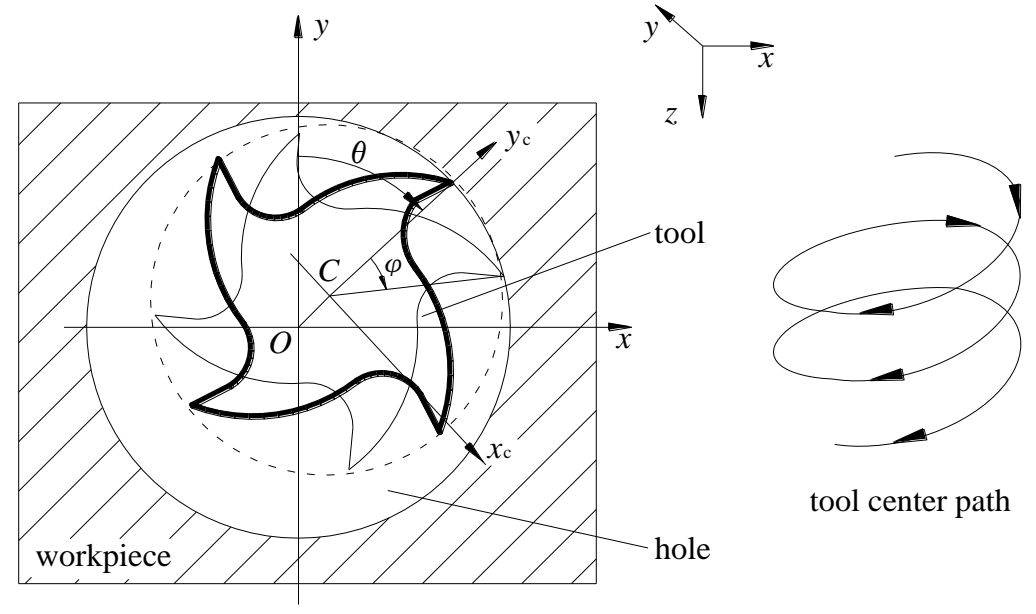

tool center path

Fig. 1 Helical milling process

In recent years, researches on the helical milling technology are gradually increasing. Denkena et al.(2008)analyzed helical milling of CFRP/titanium alloy using three sides solid carbide milling cutter blade with TiAlN coated. The results showed when the higher tangential feed speeds and lower axial feed rates were used, cutting forces would be smaller with lower hole diameter deviation. Brinksmeier et al.(2011)conducted a comprehensive analysis on the cutting force, cutting temperature and surface integrity in the helical milling and drilling of aluminum alloy/ CFRP/ titanium laminate, the results showed that helical milling technique could effectively reduce cutting force, cutting temperature and improve the hole quality. The dynamics in helical milling of titanium alloy was analyzed(Wang, et al.,2012), and the cutting force, tool wear and hole quality state were detailedly discussed(Qin, et al.,2012). Cutting force modeling in the helical milling process were simulated(Liu, et al., 2012), hole-surface topology and surface quality in helical milling process were simulated(Li and Liu,2013).

In the helical milling process, the cutting feed direction changes timely, so whatever unidirectional CFRP or multidirectional CFRP, the angle between fiber direction and cutting feed direction changes from time to time between $0-360^{\circ}$. In order to study deeply the hole quality and the factors impacting the quality in the helical milling process, the effect of material on the cutting performance needs to be studied. So this paper mainly analyzes the cutting performance related to material different to the metal in the helical milling of CFRP. The following sections present the experimental setup, and the experimental results reveal the interaction between tool wear, cutting force, delamination and hole quality.

\section{Experimental setup}

Unidirectional and multidirectional CFRP laminates with $10 \mathrm{~mm}$ thickness were respectively used in the machining process, and the length and width of the sheet was about $250 \mathrm{~mm} \times 120 \mathrm{~mm}$. Unidirectional CFRP was mainly the fiber laminate with $0^{\circ}$ along to the length direction( $\mathrm{x}$ direction), while multidirectional CFRP was mainly the repeating with $45^{\circ} / 135^{\circ} / 0^{\circ} / 90^{\circ}$ fiber direction configuration. All the experiments were performed in the five-axis CNC machining centers, a four-blade carbide milling cutter with $35^{\circ}$ helix angle, $5^{\circ}$ rake angle, diameter of $6 \mathrm{~mm}$ and TiAlN coating was used. All the hole diameters were $10 \mathrm{~mm}$. Both rotation and revolution of the tool were all in clockwise direction. Three-direction cutting forces $(F \mathrm{x}, F \mathrm{y}, F \mathrm{z})$ were measured by using a Kistler $9255 \mathrm{~B}$ dynamometer. The situation of the tool wear was analyzed using a scanning electron microscope periodically during the experiment, as shown in Fig.2. The surface quality is evaluated on basis of micrographs of the milled surfaces after experiment. 

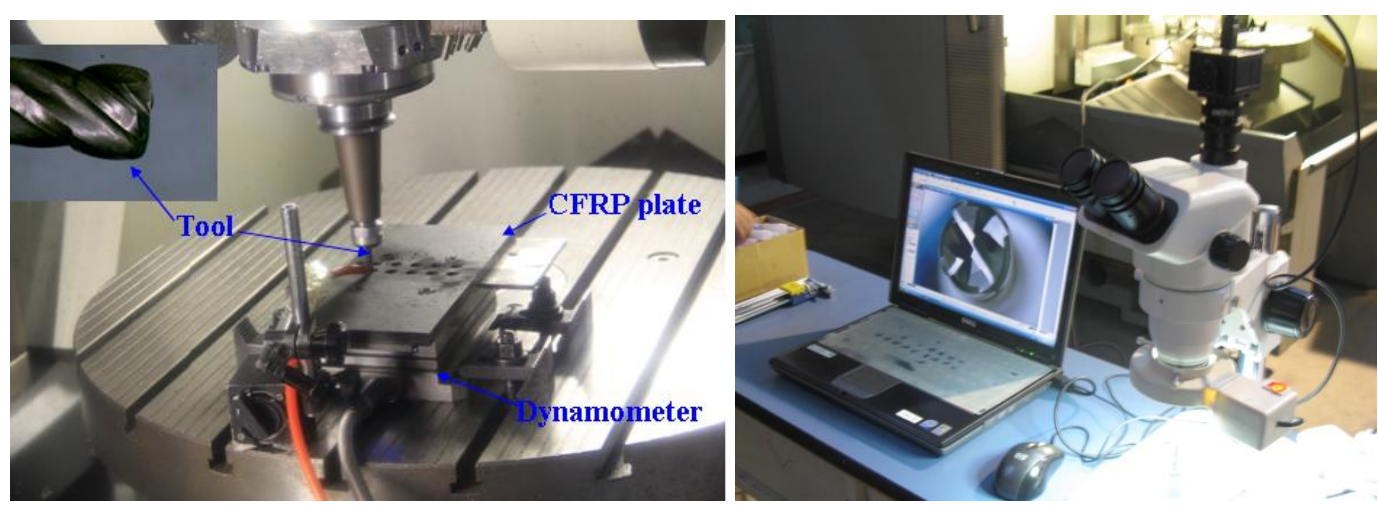

Fig.2 Experimental setup

There are several cutting parameters in the helical milling process, supposed that $n$ is spindle rotation speed(rpm), $n_{o}$ is the spindle orbital speed(rpm), and $s_{t}$ is the feed rate per tooth in tangential direction, $a$ is the cutting depth every orbit in axial direction, and tool radius is expressed as $r$, hole radius is $R$, tool teeth is expressed as $N$,thus the cutting speed

and orbital speed can be illustrated as

$$
v=\frac{2 \pi n r}{1000}
$$

$$
n_{o}=\frac{s_{t} \cdot N \cdot n}{2 \pi(R-r)}
$$

feed rate in axial direction

$$
f=a \cdot n_{0}
$$

Namely once the tool and hole-making diameter are determined, only given three cutting parameters, the movement will be basically assured. So three parameters including spindle rotation speed, feed rate per tooth in tangential direction and cutting depth every orbit in axial direction are used as cutting parameters to analyze the helical milling process.

To investigate the relationship between cutting parameters and cutting force, a full factorial experimental design method was used, the selected cutting parameters are illustrated in Table 1.

Table 1 Cutting parameters in helical milling of CFRP

\begin{tabular}{cccc}
\hline \multirow{2}{*}{ Factors } & \multicolumn{3}{c}{ Levels } \\
\cline { 2 - 4 } & 1 & 2 & 3 \\
\hline Spindle rotation speed $n(\mathrm{rpm})$ & 4000 & 5000 & 6000 \\
Feed rate per tooth $s_{\mathrm{t}}(\mathrm{mm} / \mathrm{t})$ & 0.02 & 0.04 & 0.06 \\
Cutting depth every orbit $a(\mathrm{~mm} / \mathrm{r})$ & 0.1 & 0.15 & 0.2 \\
\hline
\end{tabular}

\section{Analysis of experimental result}

\subsection{Influence of cutting parameters on cutting forces}

To easily analyze the change of cutting force, radial force can be expressed as

$$
F_{r}=\sqrt{F_{x}^{2}+F_{y}^{2}}
$$

In order to analyze the effect of cutting parameters on cutting force in the cutting process, the change of axial force and radial force are analyzed respectively for unidirectional CFRP material. The relationships between the cutting force and cutting parameters are illustrated in Fig.3, where spindle speed, feed rate and cutting depth respectively represent spindle rotation speed, feed rate per tooth in tangential direction and cutting depth every orbit in axial direction. 


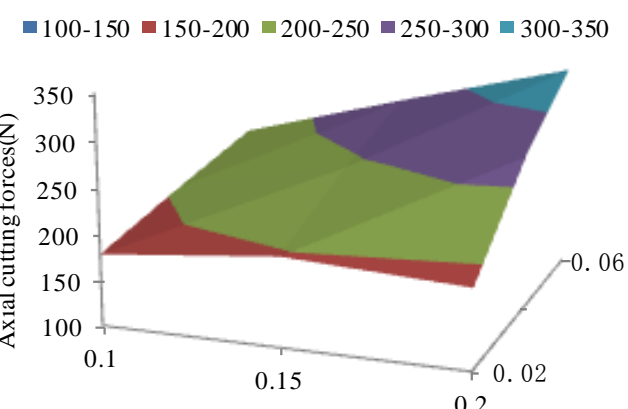

Cutting depth(mm/r)
Feed rate $(\mathrm{mm} / \mathrm{t})$

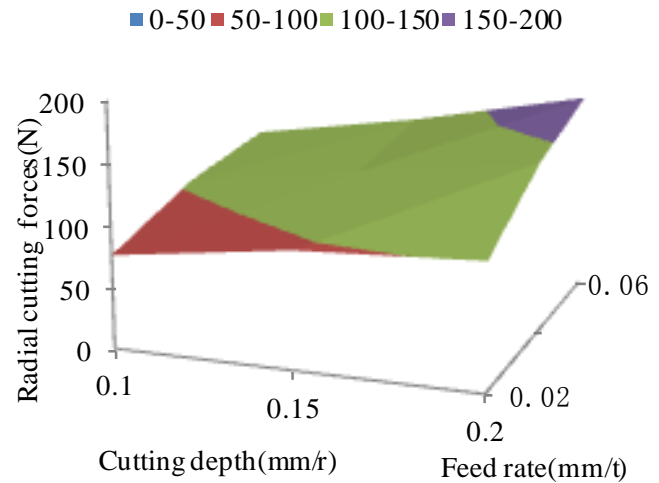

(a)

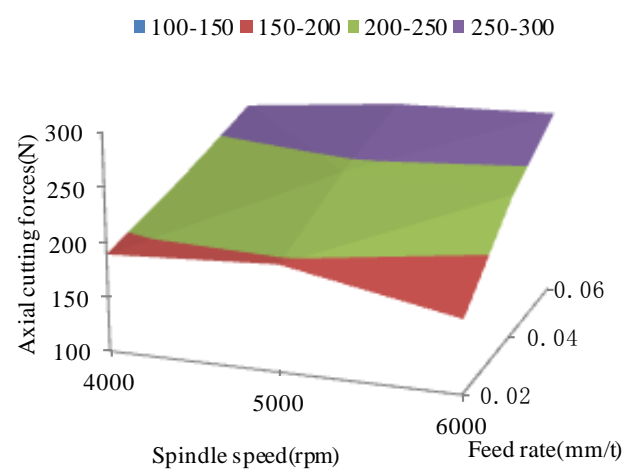

(c)

-100-150 $=150-200=200-250=250-300$

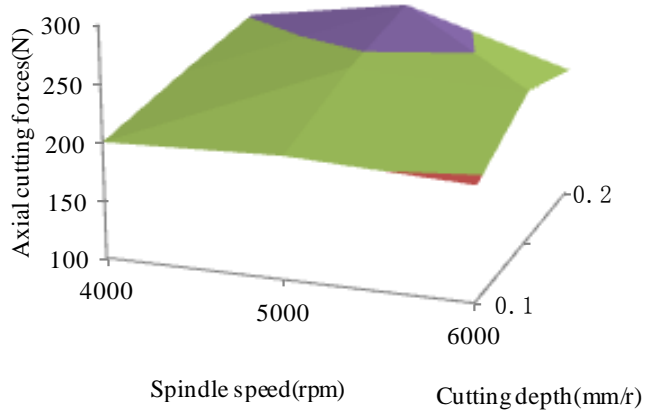

(e)

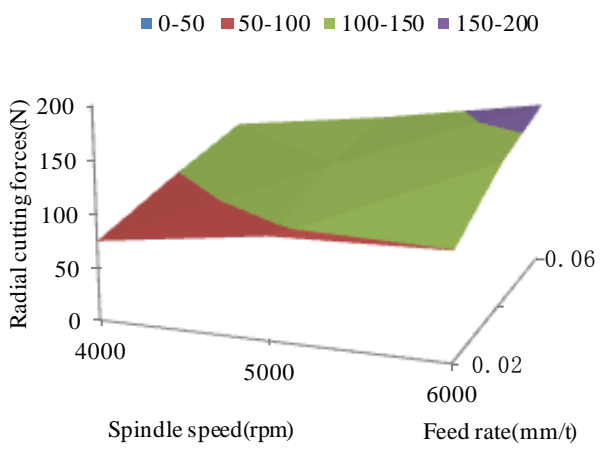

(d)

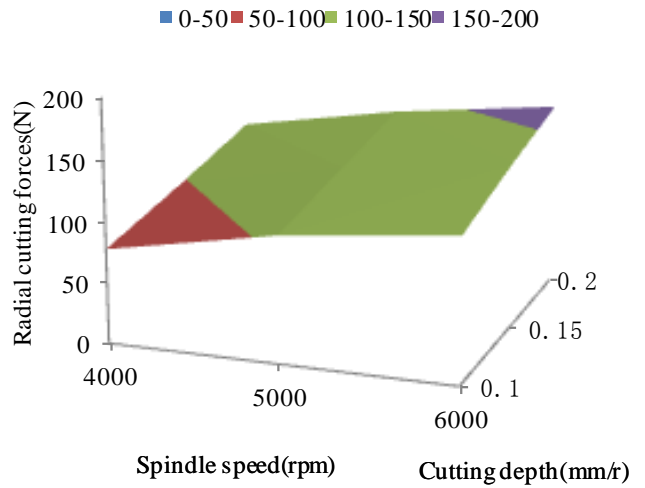

(f)

Fig.3 Cutting forces versus cutting parameters for unidirectional CFRP

Firstly the feed per tooth and cutting depth change with constant spindle speed(5000rpm), it can be seen from Figs.3(a) and(b) that radial and axial cutting forces all increase with the increase of feed per tooth and cutting depth, and the influence of cutting parameters on the axial force is larger than radial force. When the cutting depth is $0.15 \mathrm{~mm} / \mathrm{rev}$, the change of axial and radial cutting force versus spindle speed and feed rate is illustrated in Fig.3(c and d). The results show that nearly all the cutting forces increase with the increase of cutting parameters, the influence of feed rate is larger than spindle speed, and when the spindle speed lies in 5000-6000rpm, axial cutting forces show decreasing trend. When the feed rate is $0.04 \mathrm{~mm} /$ tooth, the influence of cutting parameters on the cutting force is illustrated in Fig.3(e and f). It can be seen that radial forces increase with the increase of the two cutting parameters, while axial forces increase when the cutting depth increases but when the spindle speed lies in 4000-5000rpm, axial 
forces also increase with the increase of the spindle speed, but when the spindle speed lies in 5000-6000rpm, axial forces decrease with the increase of the spindle speed. It also can be seen from Fig. 3 whatever cutting parameters are selected, axial forces(z direction) are always larger than radial direction.

Then in order to analyze the difference of cutting forces between unidirectional and multidirectional CFRP material, both axial and radial cutting force under two kind of cutting parameters in Table 1 were selected to compare, the cutting parameters selected are illustrated in Table2, $F_{z 1}$ and $F_{r 1}$ in Fig.4 are respectively axial and radial cutting forces in state 1 in Table2, $F_{z 2}$ and $F_{r 2}$ are respectively axial and radial cutting forces in state 2 in Table2.

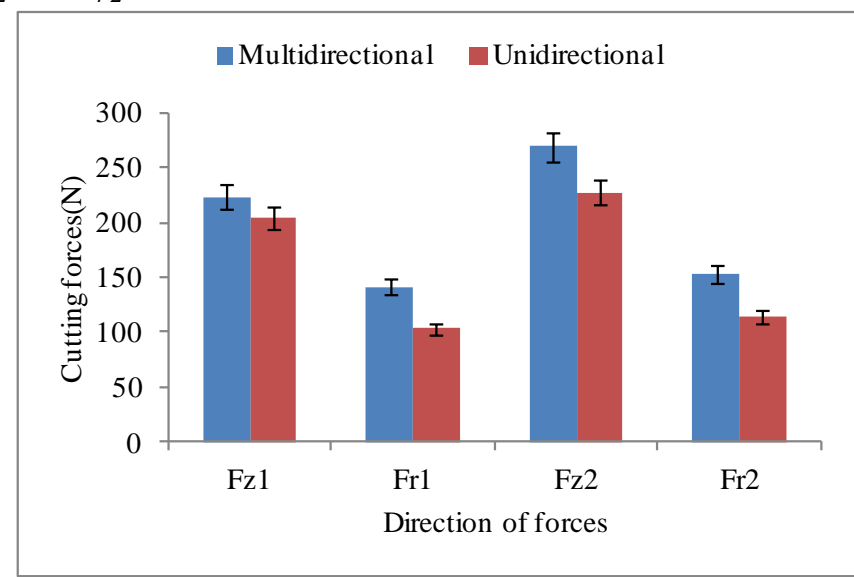

Fig.4 Cutting force comparison chart of unidirectional and multidirectional CFRP

Table 2 Cutting parameters of state in Fig. 4

\begin{tabular}{c|c|c|c}
\hline \hline State & $\begin{array}{c}\text { Spindle rotation speed } \\
(\mathrm{rpm})\end{array}$ & $\begin{array}{c}\text { Feed rate per tooth } \\
(\mathrm{mm} / \mathrm{t})\end{array}$ & $\begin{array}{c}\text { Cutting depth } \\
(\mathrm{mm} / \mathrm{r})\end{array}$ \\
\hline $1(\mathrm{Fz} 1, \mathrm{Fr} 1)$ & 5000 & 0.04 & 0.15 \\
\hline $2(\mathrm{Fz} 2, \mathrm{Fr} 2)$ & 6000 & 0.06 & 0.2 \\
\hline
\end{tabular}

As illustrated in Fig.4, cutting forces about multidirectional CFRP are always slightly larger than unidirectional CFRP. Because of the single-ply thickness of fiber is $0.125 \mathrm{~mm}$, and the tool feed rate per orbit in axial direction(cutting depth) is between $0.1-0.2 \mathrm{~mm}$, therefore the feed every orbit may less than or more than a layer of fibers. The main reason for this phenomenon lies in that the multi-layer composite fibers are composed of fibers with different angles, and cutting forces suffered of the tool is different in each layer, namely processing difficulty of multidirectional fiber plies is greater than unidirectional CFRP.

In short, the influence of cutting parameters on the cutting force is relative notable, and cutting force will vary depending on the fiber plies way.

\subsection{Tool wear}

Excessive tool wear will induce fiber pullout, particle fracture, delamination and debonding at the fiber or particle and matrix interface(Rawat \& Attia,2009). Because carbon fibers are extremely abrasive nature, the cutting edge would occur serious wear in the machining process. The cutting level of 2 in Table 1 about unidirectional CFRP is selected as a basis to analyze the tool wear.

Tool wear is generally experienced three cycles with initial wear, normal wear and severe wear, and showing the bathtub curve shape(Rawat \& Attia,2009). The wear states of the cutting edge in the helical milling process investigated with electron microscopy are shown in Fig.5. It shows that the tool tip of bottom cutting edge occurs a more severe wear in Fig.5(a) without the chipping and breakage while machining of metal. The wear belongs to abrasive wear, and there is a clear mark at the surface of the tool, which is the most common and most serious harm to the tool wear form. The reason lies in CFRP material with the high hardness scratches the surface of the tool. The wear state of the tool periphery edge is illustrated in Fig. 5(b), it can be seen that the coating of the side edge surface has been off with a large number of CFRP powder adhesion without obvious severe wear. 


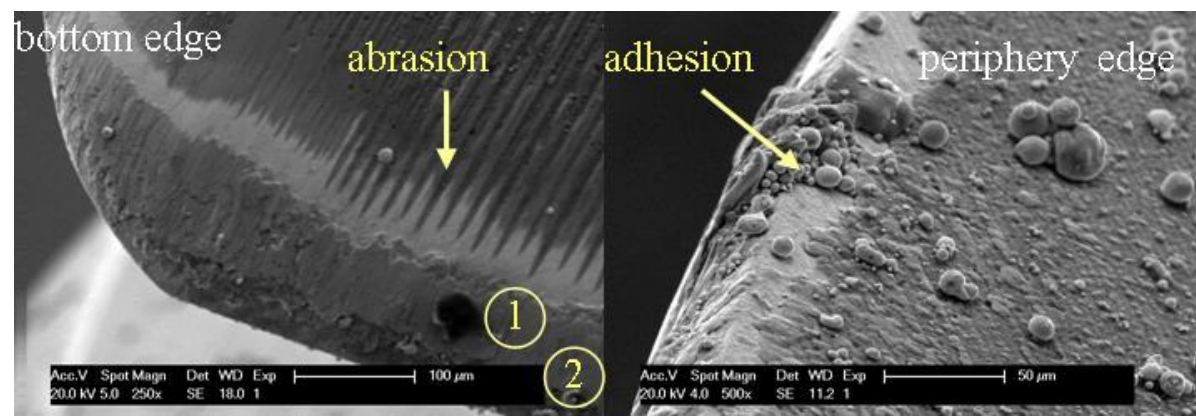

(a) Bottom edge

(b) Periphery edges

Fig.5Wear state in different position of the tool

EDX (S) is used to analyze the wear state of the bottom edge, the results are shown in Fig.6, and the percentage of worn elements and atomic weight lists in Table 3. The change of elements in different locations is different at the bottom edge. Since the tool is TiAlN coated, element $\mathrm{N}$ should be exist in the worn tool element, but the test results show element $\mathrm{N}$ is not there in two different locations, replaced by $\mathrm{V}$ and $\mathrm{W}$ elements.
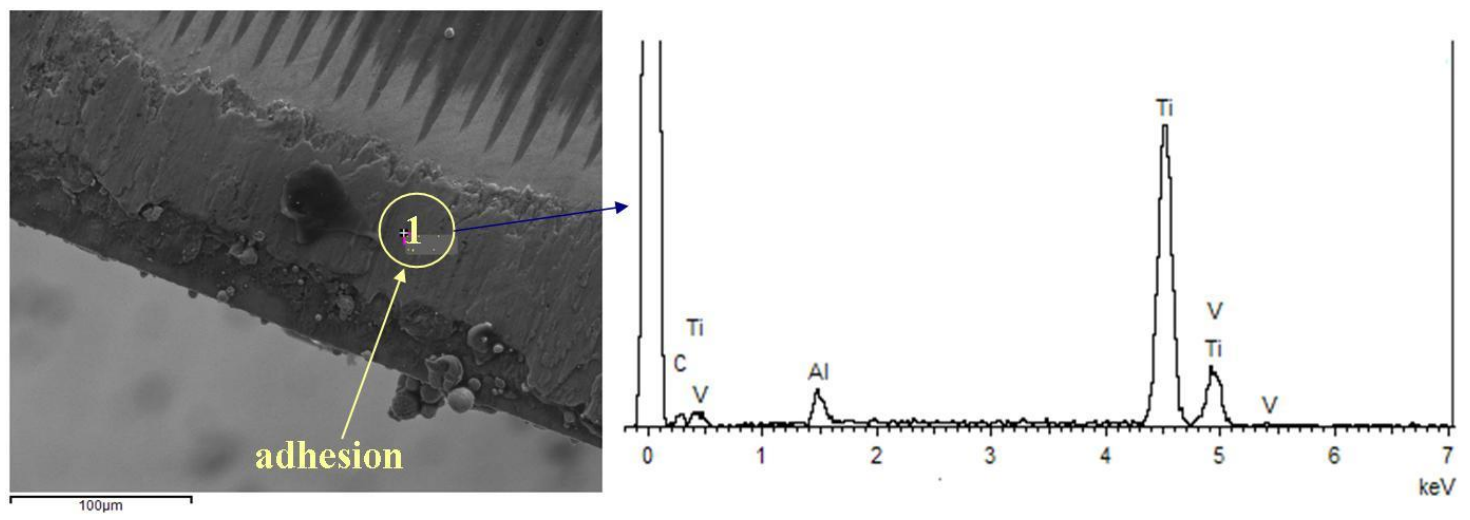

(a)
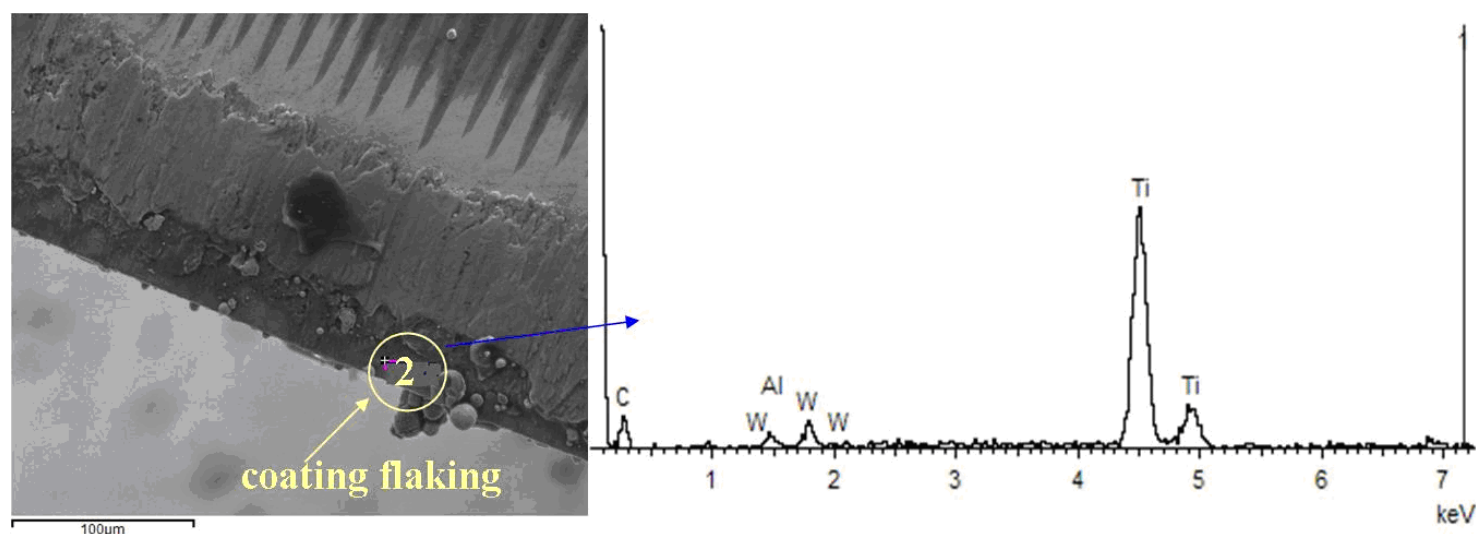

(b)

Fig.6 EDS analysis after wear in the bottom edge of the cutter

Table 3 Worn elements and atomic weight

\begin{tabular}{cccccccc}
\hline \hline & Element & $\mathrm{C}$ & $\mathrm{Al}$ & $\mathrm{Ti}$ & $\mathrm{W}$ & $\mathrm{V}$ & Total weight \\
\hline \multirow{3}{*}{ Fig.6(a) } & Weight(\%) & 20.16 & 4.41 & 70.99 & $/$ & 4.44 & 100 \\
& Atomic(\%) & 30.59 & 5.85 & 60.44 & $/$ & 3.16 & 100 \\
\cline { 2 - 7 } Fig.6(b) & Weight(\%) & 10.27 & 1.66 & 80.27 & 7.80 & $/$ & 100 \\
& Atomic(\%) & 51.62 & 1.89 & 45.18 & 1.31 & $/$ & 100 \\
\hline
\end{tabular}


In the Fig.6(a), the coating does not fall off, a small amount of element V appears in the surface of the tool, the most likely reason is that affinity action takes place in a short process for the through-hole, because in the cutting process, the titanium plate was place below the CFRP plate, the $\mathrm{V}$ content is about 3.5\%-4.5\% for the Ti-6Al $-4 \mathrm{~V}$.While most coating is off in the Fig.6(b), W element appears in the surface of the tool after worn, which explains the substrate is exposed when the coating is off. Since the tool substrate is cemented carbide, which is a high hardness refractory metal carbides (WC, TiC), the main component is micron powder with a cobalt (Co) or nickel $(\mathrm{Ni})$, molybdenum (Mo) as binder.

\subsection{Relationship between tool wear and cutting forces}

CFRP is highly wear-resistant material, the tool cutting edge will occur breakage and powerful wear in the cutting process. As the number of holes increase, tool wear increases, and the cutting forces suffered will increase. However, monitoring of tool wear offline at any time is not realistic in the cutting process, cutting state changes in the cutting process can verify the tool wear state. In order to analyze the impact of tool wear on the cutting force, the same tool (rake angle of 5 degrees, the helix angle of 35 degrees, TiAlN coating), the same workpiece material, the same cutting parameters (spindle speed of 5000 rpm, feed rate per tooth in tangential direction is $0.04 \mathrm{~mm} /$ teeth, cutting depth every orbit $0.1 \mathrm{~mm} / \mathrm{rev}$ ) are selected to carry out experiment. The tool was removed to observe using tool microscope every 5 to 10 holes after processing. The results show there is not significant fragmentation chipping and larger damage of tool in metal cutting process, the tool appeared more serious wear, more and more obvious white layer appears in the bottom of the cutting edge, and side edge is also shown a significant signs of wear, the wear state basically like Fig.6. Due to hardness of CFRP material, tool wear is mainly abrasive wear, thus the detail tool wear phenomenon is described in part 3.2. But the cutting force is measured in real time, which is very sensitive and can really reflect cutting state. Thus here the relation between cutting force and hole number are illustrated, instead the relation between cutting force and tool wear quantized value, the result is illustrated as in Fig.7.

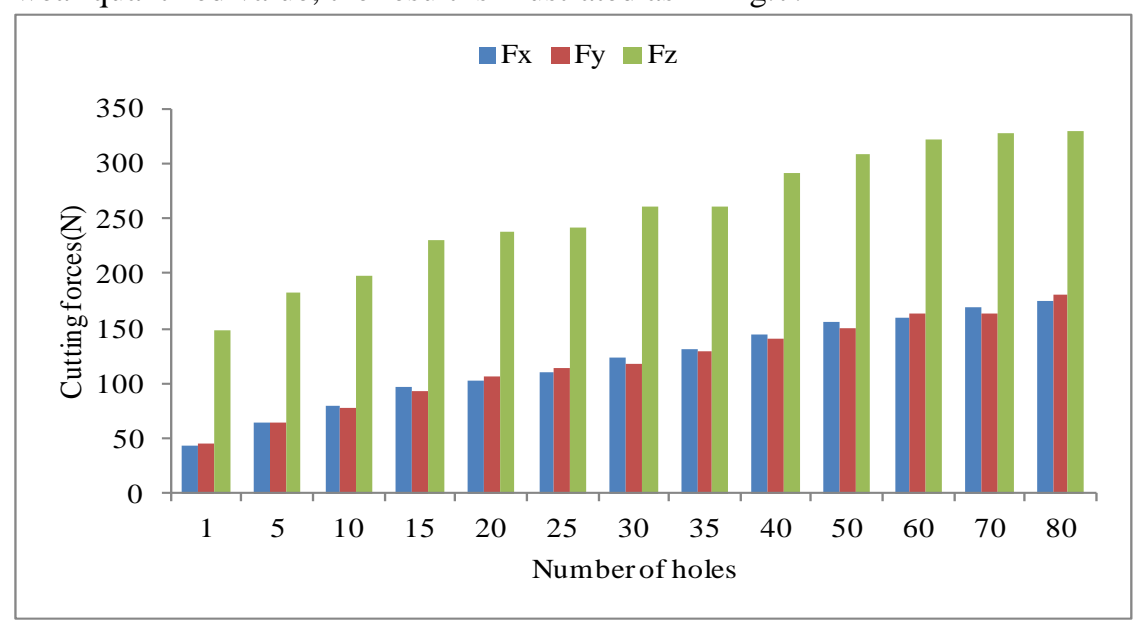

Fig. 7 Effect of tool wear on the cutting forces

It can be seen from Fig.7 that the cutting forces in three directions will increase with the hole numbers, and with the increase of the number of machining hole, tool wear has intensified. That is, the cutting force will increases with the increasing of tool wear. When the 15th holes are machined, three-direction cutting forces increases dramatically. For example, in the processing of the first 5 holes, three direction cutting forces( $\mathrm{x}, \mathrm{y}$, and $\mathrm{z}$ direction) increase about $45.8 \%$, $41.7 \%$ and $24 \%$ relative to the first hole respectively, while in the 10th hole machining, the cutting forces relatively increase by $24.8 \%, 19.6 \%, 8.5 \%$ respectively relative to the fifth hole, in the processing of the 15 th holes, cutting force increase by $20.5 \%, 21.7 \%, 16 \%$ respectively relative to the tenth hole, while in the processing of the 20th hole, cutting force increase by $6.5 \%, 13.6 \%, 2.9 \%$ relative to the first 15 holes, respectively. The increasing trend is gradually slow. Obviously, there is very close relationship between cutting forces and tool wear in the helical milling of CFRP process, and the influence of the tool wear on the cutting force is more significant.

In summary, the effect of the tool wear on the cutting forces is positive. The reason lies in when the wear appears in the back face of the tool, the formation of small facets forms, and the greater is the flank wear, the greater is the small edge surface area, then the contact area between the cutter flank and the workpiece will increase, thus all three 
cutting forces increase. Because the cutting tool is not significantly worn during a short cut, the effect of tool wear on the cutting forces is not too large. But if the tool wear is relative large, cutting forces may increase abruptly. Therefore, this comparison can be used to judge whether the tool is still good or not.

\subsection{Hole quality}

Hole quality is the most critical factor affecting the appliance, therefore, hole quality and the affecting factors in helical milling of CFRP need to be analyzed detailedly.

\section{(1) Delamination of the top layers}

Microscopic images of holes are observed using ultra-depth three-dimensional microscope KEYENCE VHX-600E, respectively, for unidirectional and multidirectional CFRP material, good and poor quality are selected to comparatively analyze after helical milling process, the results are shown in Fig.8.

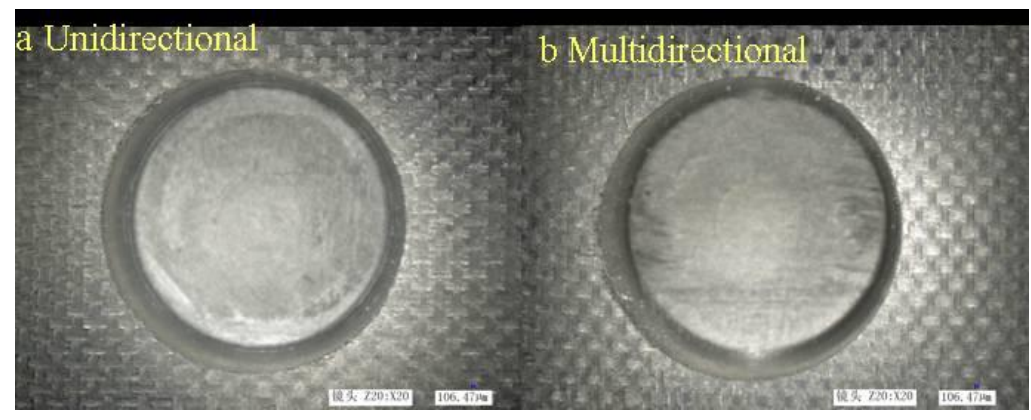

(a) Good entry hole quality

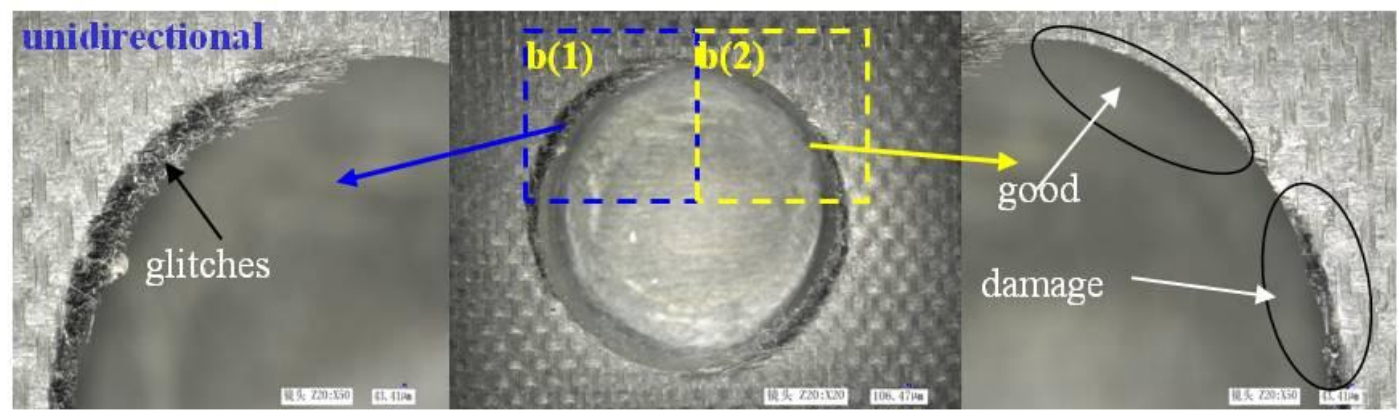

(b) Poor entry hole quality

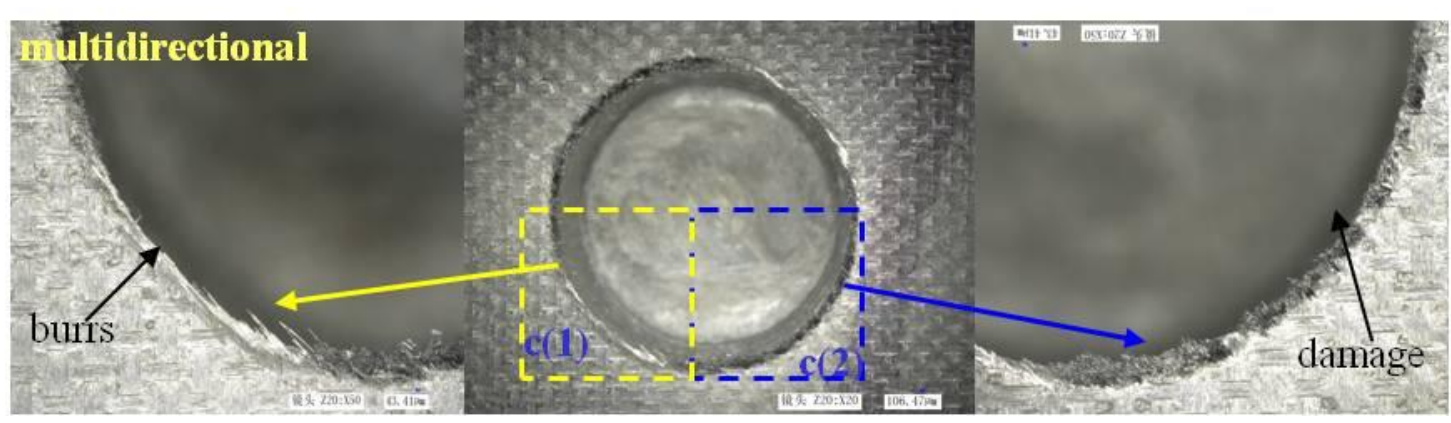

(c) Poor entry hole quality

Fig.8 Ultra-hole depth microscopic analysis of hole quality

The entry hole quality is good no matter for unidirectional and multidirectional CFRP in Fig.8 (a), but the quality is poor in Fig.8 (b) and Fig.8 (c) accompanied by delamination of the top layers in the machined edges. For Fig. 8 (a), the hole edge quality is good whichever direction is, it is the hole machined using a sharp tool, the tool wear does not occur, the fiber can be cut clearly and no delamination occurs. The tool wear appears in Fig.8(b) and Fig.8 (c), thus the hole edge quality is serious. Here the fiber cutting angle is defined as the angle between fiber direction and feed 
direction, thus in the range of fiber cutting angle $45^{\circ}-180^{\circ}$ as shown in Fig.8(b1), obvious glitches can be seen in the hole edge, and the burr direction is consistent with the $0^{\circ}$ direction fiber; while for the $0^{\circ}-45^{\circ}$ fiber cutting range, the hole edge quality is relatively good with smooth edge of the hole, as shown in Fig.8(b2).

For multidirectional CFRP, the typical poor hole-making quality is illustrated in Fig.8(c), in the range of Fig.8(c1), more burrs and damage appear, but burr height and extent of the damage is significantly lower than unidirectional CFRP, while in the rest of the range, the glitches are not too serious, as shown in Fig.8(c2), but the whole hole edge quality is not very good with large damage.

Namely, whatever unidirectional or multidirectional CFRP, the fibers can be cut clearly and no delamination occurred using a sharp tool. While cutting using a worn tool, it is found that delamination only appears in certain regions on the machined edges, the rest of the machined edge is free of delamination despite the very high tool wear for the unidirectional CFRP. Tool wear is a key factor for the occurrence of delamintion.

\section{(2) Quantitative analysis of hole quality}

Delamination factor is used to express the entry delamination index, which is the ratio of the maximum diameter of entry delamination around the hole and ideal diameter of the holes. It can be seen from Fig.9(a) that delamination factors increase with the tool wear state(number of holes), namely, tool wear would influence the delamination in the helical milling of CFRP, and delamination factors are basically lied in 1.05 1.12. In addition, take the hole diameters of unidirectional CFRP as the basis for analysis, the results are also shown in Fig.9(a). The hole diameter error is between $\pm 0.01 \mathrm{~mm}$, and the tolerance of $10 \mathrm{~mm}$ diameter with IT8 should be $22 \mu \mathrm{m}$, which shows that the diameter error of the holes meet the requirements.

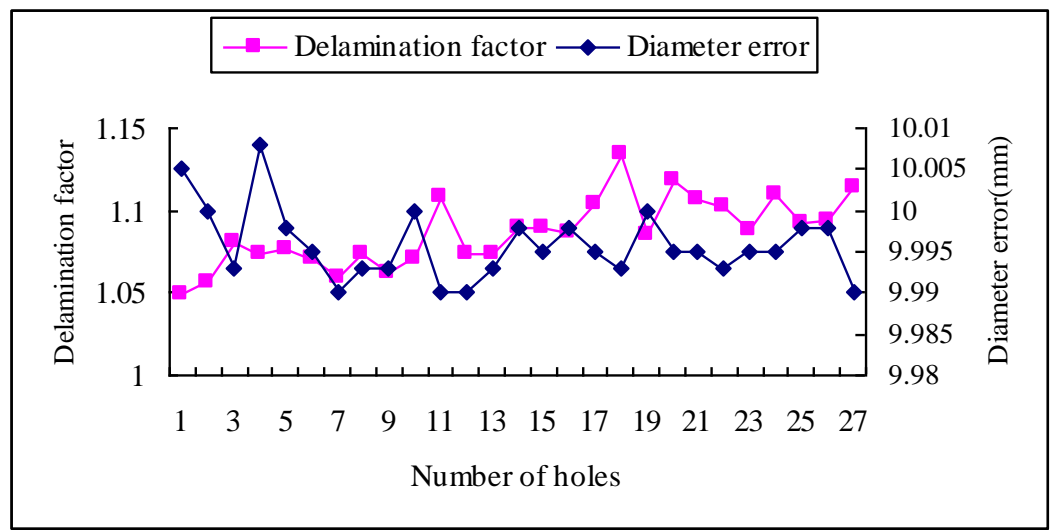

(a) Delamination factor and diameter error

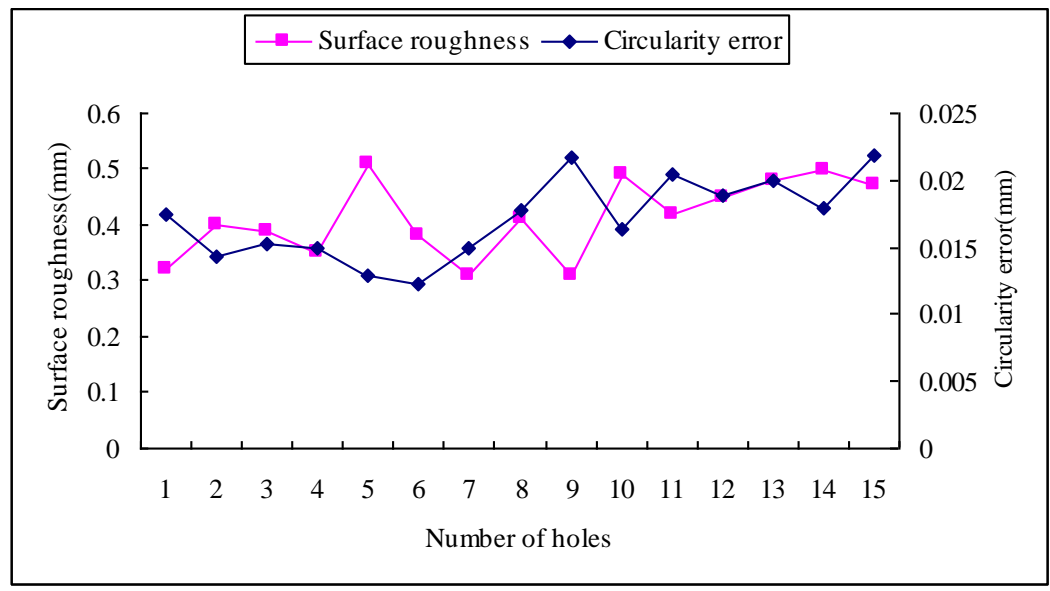

(b) Surface roughness and circularity error

Fig. 9 Analysis of hole quality quantitatively

The circularity error and surface roughness of holes in helical milling process are shown in Fig.9(b),with the increase of hole number, circularity error and surface roughness show small increasing trend, and the circularity error is 
about $10-20 \mu \mathrm{m}$, while surface roughness Ra is about 0.3-0.6 $\mu \mathrm{m}$.

In short, tool wear would impact delamination factor, while the effect on the diameter error is not obvious, the holes show the contraction state with the number of holes increase. The effect of tool wear on the circularity error and surface roughness shows small increasing trend.

\section{Conclusions}

This investigation achieved an understanding in helical milling of CFRP and led to the following conclusions:

1. No matter axial force and radial force, cutting forces increased with the feed rate and depth of cut, and radial force increased with the increase of spindle rotation speed, while the spindle rotation speed was larger than 5000rpm, axial force would decrease with the increase of spindle speed, whereas, axial force would increase with the increase of spindle rotation speed. In addition, the axial forces were always far larger than radial forces about 5 -fode.

2. Cutting force would increase with the increase of tool wear, and the influence trend of tool wear on the cutting forces was more obvious in helical milling of CFRP, which showed that tool wear was serious in machining of CFRP, in addition, cutting forces was larger in milling of multidirectional CFRP than unidirectional CFRP.

3. Tool wear state was analyzed through microscope and EDX. Due to the material character of CFRP, tool wear showed increasingly serious phenomenon in the cutting process with abrasive wear. And for the TiAlN coating, element $\mathrm{N}$ was all replaced with $\mathrm{W}$ and $\mathrm{V}$ element, which showed that coating was partly off in the machining of CFRP.

4. The tool wear problem directly influenced the entry delamination state. When cutting with a sharp tool, there was nearly no delamination, when the tool wear occurred, the entry delamination scope became large. For the unidirectional and multidirectional CFRP, entry delamination showed different state.

5.Entry delamination factor, diameter error, surface roughness and circularity error were used to evaluate hole quality quantitatively, with the increase of hole number, circularity error and surface roughness showed small increase trend, delamination factor increased with the tool wear state, and diameter error was almost unchanged considering the tool wear.

\section{Acknowledgments:}

The authors would like to thank the financial support through Natural Science Foundation of Hebei Province, China (Contract No.E2014501077), Natural Science Foundation of China (Contract No. 51275345) for the supports of this work.

\section{References}

Brinksmeiere E, Fangmann S, Rentsch R. Drilling of composites and resulting surface integrity. CIRP Ann Manuf Technol 2011, 60:57-60.

Denkena B, Boehnke D, Dege JH. Helical milling of CFRP-titanium layer compounds. CIRP J Manuf Sci Technol 2008,1:64-69.

Durão LMP, Goncalves DJS, Tavares JMRS, Albuquerque VHC, Vieira AA, Marques AT. Drilling tool geometry evaluation for reinforced composite laminates. Compos. Struct 2010,92:1545-1550.

Hintze W, Hartmann D, Schütte C. Occurrence and propagation of delamination during the machining of carbon fibre reinforced plastics (CFRPs) - An experimental study. Compos Sci Technol 2011, 71:1719-1726.

Iliescu D, Gehin D, Gutierrez ME, Girot F. Modeling and tool wear in drilling of CFRP. Int J Mach Tools Manuf 2010,50: 204-213.

Karnik SR, Gaitonde VN, Rubio JC, Correia AE, Abrao AM, Davim JP. Delamination analysis in high speed drilling of carbon fiber reinforced plastics (CFRP) using artificial neural network model. Mater Design 2008,29:1768-1776.

Lachaud F, Piquet R, Collombet F, Surcin L. Drilling of composite structures. Compos Struct 2001,52: 511-516.

Liu CY, Wang G, Matthew S. Dargusch. Modelling, simulation and experimental investigation of cutting forces during helical milling operations. Int J Adv Manuf Technol 2012;63:839-850.

Li ZQ, Liu Q. Surface topography and roughness in hole-making by helical milling. Int J Adv Manuf Technol 2013,66:1415-1425. 
Qin XD, Gui LJ, Li H. Rong B,Wang DS, Zhang HZ, Zuo GC.2012.Feasibility study on the minimum quantity lubrication in high speed helical milling of Ti-6Al-4V. J Adv Mech Des Syst 2012,6(7):1222-1233.

Rawat S, Attia H. Wear mechanisms and tool life management of WC-Co drills during dry high speed drilling of woven carbon fiber composites. Wear 2009,267:1022-1030.

Wang HY, Qin XD, Ren CZ, Wang Q. Prediction of cutting force in helical milling process. Int J Adv Manuf Technol 2012,58(9-12):849-859.

Zhang HJ,Chen WY,Chen DC. Investigation of the exit defects in drilling carbon fiber reinforced plastic plates. J Mech Eng 2004,40(7):150-155. (in Chinese) 